\title{
LIFELONG LEARNING AS A PREMISE FOR BUILDING THE LEARNING ORGANIZATION IN THE ROMANIAN SMES
}

\author{
Roxana Mironescu \\ "Vasile Alecsandri” University of Bacau, \\ roxy_mironescu58@yahoo.com \\ Andreea Feraru \\ "Vasile Alecsandri” University of Bacau \\ andreea_feraru26@yahoo.com \\ Catalin Drob \\ "Vasile Alecsandri” University of Bacau \\ totanul@yahoo.com
}

\begin{abstract}
To become more competitive, the SMEs in our study should encourage learning at all the organizational levels, meaning becoming learning organizations. The lifelong learning has become a vital necessity of the contemporary society, it is a theoretical principle and it acts to describe a specific reality of our century. The lifelong education should not be conceived as a mere preparation for life but as an important dimension, a continuous existential one, whose duration is overlapped with the life span. This research aims to capture the boundaries, inside the SMEs, where the organizational culture acts as an impulse for learning. The used investigation method was based on the findings and attitudes revealed by a questionnaire survey, on a systematic observation upon the phenomena and from the synthesis of some previous studies in this area. The paperwork emphasizes the importance of the strategic orientation towards knowledge management, stressing that the main advantage that such an economic entity as a SME can have is the ability to systematically and continuously exploit the obtained knowledge. The organizational learning may be even a means to achieve certain strategic objectives.
\end{abstract}

\section{Keywords}

learning organization; organizational culture; knowledge management; intellectual capital; lifelong learning

\section{JEL Classification}

M10

\section{Introduction}

The learning organization is the tool for adaptation to the knowledge economy in its dynamic route. As an effect and a cause of the globalization, as an effect of the dramatic increase of the technological innovations, the explosion of knowledge has transformed everything, from how the goods and services production may be done, to the State's role, the public sector size and its valences, to reinventing the concepts of the market economy and of the capitalism. Peter Senge (Senge, 1999) is devoted to the change which ensures learning and to the learning that facilitates the change, both for people and organizations. Nowadays, we can build "the learning organization", as an formal background where people continually expand their capacity to create the results they truly desire, where new patterns of thinking are encouraged, where the collective aspiration is free and where people are continually learning how to learn together (Senge, 1999). To do this, managers must learn to detect abilities and how to properly use them. 
The emergence of the idea of "learning organization" is explained by concepts such as "learning society", a definition which was conducted by Donald Schön (Schön,1991). He provided a theoretical framework for the relationship between life experiences in the context of change and of the permanently growing need for learning. The loss of the stability in the social, economic or cultural practice has oriented our society and all its institutions towards a continuous transformation. We must learn to understand, to guide, to influence and to manage these transformations, in other words we must become the learning upholders. Humanity must aware of the development of the organizations which are "learning systems", as systems able to contribute to their own continuous transformation. Donald Schön, followed by Chris Argyris (Argyris,1978) developed a set of important concepts regarding the organizational learning. Of a special importance for the further development of this concept was their interest in the feedback of learning, learning in a double loop feedback. The productivity and the competitiveness are general functions of the knowledge generation and of the information processing; firms and territories are organized in worldwide production, management and distribution networks production, the basic economic activities are global and all that induces the ability to consistently work in real time, at a planetary scale. The education is no longer limited to what is accomplished in school, but it continues after graduation (post-school education, postgraduate, various forms of training, including self-education), the permanent education do not identify itself with any of the institutions of adult education, but it can be presented as a complex and dynamic system, benefiting from a range of educational and organizational conditions and a proper staff able to prepare and to facilitate the lifelong learning concept.

\section{Problem statement}

Managers may think that leading their organizations towards learning is only a matter of articulating a clear vision, giving employees the right incentives, and providing means of training. This assumption is not merely flawed-it's risky in the face of the intensified competition, of the technological advances and of the shifts in customer preferences. Organizations need to learn more than ever as they confront these amount of forces. Each company must necessarily become a learning organization.

There is not a consensus among experts in defining "learning organization", therefore, we only cited certain definitions, given over the time:

- "The organizations that have clear objectives, rules of monitoring and the capacity for learning new behaviors derived from the exploration of the past experiences" (Cyert and March ,1963);

- "The organizations characterized by thinking more deeply about the organizational problems, related to the restructuration through their individuals" (Simon, 1969);

- $\quad$ "The organizations that develop the understanding of the reality, carefully noting the results" (Hedberg, 1981);

- "The organization where a group of people work together, to achieve improvement of their collective skills and capabilities, in order to obtain the desired results" (Senge, 1990);

- $\quad$ "A type of organization which is always able to provide, innovate and find more effective means for its goals achievement" (Mahapatro, 2010).

However, the potential of the adult learning has not been yet fully exploited: participation in lifelong learning greatly varies and it is unsatisfactory in many E.U. countries, and well below the E.U. targets. Generally speaking, the EU-wide strategy for cooperation in education and training is provided in "ET 2020", a strategic document adopted in May 2009. Containing certain actions at all the levels of the 
education and training systems, this programmatic document highlighted four major objectives, such as:

- Promoting the lifelong learning and encouraging the students' mobility;

- Improving the quality and the efficiency of the education and training;

- $\quad$ Promoting the equity, the social cohesion and the active citizenship;

- Enhancing the creativity, innovation and the entrepreneurship.

This compendium includes certain official documents issued by the three main decision-making bodies of the E.U.: the European Commission, the European Council and the European Parliament, as follows: The Strategy for European Cooperation in Education and Training (Strategic Framework for EU cooperation in E\&T 2020, 2000); the documents to put into practice the E.U. programs to support the policy framework for education and lifelong learning; the lifelong learning strategies; the higher education reform; the policy framework of the university-business dialogue; programs that support higher education, including the Bologna Process; support programs for adult education and training; programs supporting the adult initial education; measurement of the progress in education and training (statistics, indicators and benchmarks overview). The education and the training policies have received a boost with the adoption of the Lisbon Strategy in 2000, the overall European program focusing on the economic growth and on the job creation. This strategy recognized knowledge, innovation and business and the educational environment they generate, as the most valuable assets of the E.U., especially in the context of the increasing global competition. So, the E.U.'s member states and the European Commission have strengthened the cooperation which started in 2009, with a "strategic framework for the European Cooperation in Education and Training" (Strategic Framework for EU cooperation in E\&T 2020, 2000), as a follow-up to the Early Education.

The long-term strategic objectives of the E.U.'s education and training policies are:

- $\quad$ Making the lifelong learning and the mobility become a reality;

- $\quad$ Improving the quality and the efficiency of the education and training;

- $\quad$ Promoting equity, social cohesion and active citizenship;

- $\quad$ Enhancing the creativity and the innovation, including entrepreneurship, at all levels of the education and training.

As we refer to the Romanian realities, in the last twenty years, the adult learning and education were upgraded and this field of activity was also influenced by the major reforms that have occurred in the Romanian socio-economic and legal conditions. The purpose of these reforms was to raise the level of education and improve the school education with the extension of education, reducing drop-out rates near the EU's average, and develop the adult education. The adult education and lifelong learning has become a key component of this system, which appears to be affected by the fundamental changes in the internal socio-economic realities. The socio-economic context in Romania is quite paradoxical: while GDP and the primary statistical data related to employment reflects the fact that we are close to the E.U. average, the actual trends, for example, on the adult participation in learning lifelong indicates that social and regional problems are quite serious. The country joined European Union at the 1st January 2007. Despite the implemented reforms during the last twenty years, Romania remains dependent on the pendulum effect, concerned to stabilize the financial areas, the public administration, the regional planning and the development systems. At the present, as a result of these reforms and changes, Romanian society experiences a severe economic, social and individual crisis, a confusion of values, ethics and beliefs.

The demographic figures and trends for the former socialist countries such as Romania signal that the social and the economic transformation is followed by a significant decline in population, together with an unequal distribution of the welfare. 
The Romanian population is expected to significantly age till 2050 and the unemployed retired ratio is growing quickly. The trends influence the mobility and the migration towards other countries in Europe or elsewhere and the impact of the social instability makes the adult learning and education to be difficult and challenging. These issues are, all together, real problems and the national programmes have made great efforts, trying to improve the active living and ageing, focusing on urging older people to re-enter to the labor market and in the community life. Another important factor in the Romanian society and economy is the external migration that has impacted the adult learning and education. Since E.U. accession, a significant part of the economically active population has moved for employment in better-paying countries and, as a consequence, fields of activity like constructions, tourism, health and some others are struggling with a lack of human resources in the labor market. We can mention here the important brain-drain to the UK or Canada, USA. The Romanian economy has turned into a market-oriented open economic structure. Since the accession to the E.U., the Romanian economic and social policies, such as the national programmes involving the adult education, have been developed to help economic regeneration, to reduce the high unemployment rate through social policies, and to create a balance between the economic interests and the social needs for stability. The topic of the new skills and new basic skills, according to the White Paper on Education and to the Memorandum on Lifelong Learning, demonstrates the need for developing the adult education and the lifelong learning, especially for those people over 35 years old, with basic illiteracy or functional illiteracy, and with prior difficult experiences in education or in training programmes (often because of the unemployment or retirement).

\section{Purpose of Study}

The research aims to capture the boundaries where the organizational culture acts as an impulse for learning inside the SMEs, especially in the present, in Romania. We wanted to underline where is the limit of understanding of the importance of training inside the organizations and the level of tolerance of bad habits transferred in performance costs.

The innovative culture is based on transmitting information towards people. Managers who require sustainable results know they should give something in exchange, they must update the information able to "talk" about the interests, the concerns, the values and the principles of the company, about its successes and failures, about the common present, past and future, about people, their results and dreams. Regardless of the method chosen, either regular newsletter addressed to all the employees, or a wall panel, or special regular events, informal meetings or annual conferences, the managers have a duty to transmit information in the system, the more diversified the better. It is desirable to share more positive information, but all the information can transmit large and relevant messages, beyond the conscious to the employees. As medium and long term effects, the employees will understand what and why they are required to do, mainly special or new things, they will understand change as an organizational constant, how to act or react independently, facing the changes, but in accordance with the organizational values, what decisions to take in the right time. And so, people learn to generate solutions, to be creative, to come up with new ideas. The employees understand that in today's society they are paid for the usual tasks but also for their creativity. They are paid for the proper execution processes, or production, but also they are paid to be alert, to notify changes or opportunities and generate ideas and added value. Who understands this environment remains innovative, remains in the market, who do not understand will continuously contribute to a non-business attitude and will end up by leaving the organization. There are 
enough theoretical considerations related to the design of an organizational culture encouraging the development of "learning organization" and the lifelong learning for the employees.

The Romanian culture of the adult education has a long and agitated history. The specialized institutions continuously tried to educate more and more people and to disseminate professional knowledge, mainly towards the country sides. The practical adult education was far more advanced than any early theoretical construction trying to describe the education and learning of adults. Certain modern ideas about the adult education and the adult learning were theorized only from the beginning of the 20th century and were strongly influenced by the psychological and sociological approaches in the science of education, such as studies made by The Romanian Social Institute (RSI) founded by Dimitrie Gusti. After the World War II, the adult and their continuous education was dominated by the vocational aspects and by the sociocultural organizations specialized in leisure activities combined with education and training. In the recent times, the adult education has become a developing and changing part of the educational system. Until 2000, the changes undertaken demonstrated that there was a lack of governmental plans, few structural actions that could prevent incidental moves, and too many ambiguous responses from the labor market regarding the shift to a new social, economic and political system. In the last ten years, the governmental actions shifted towards a more coherent strategic development.

After the change of the regime in 1989, two periods of adult education had a significant impact on later developments:

- 1990 - 1993, when there was a decreasing attention paid to finding out ways of the general chaos of an upside-down political system. Adult education was almost forgotten; only some minor changes were made in order to prevent radical reform;

- 1993 - 1997, there was a phase of rebuilding, that focused on the adult education strategy. The state implemented a framework for a new and decentralized educational and training environment. As the system of the adult education can change and develop freely, it became fragmented, making it difficult for the officials to have any impact;

- After 2000, the government intended to implement the standards for the evaluation of the adult education providers, action mentioned in the Action Plan on Adult Learning in Romania.

The National Agency for Evaluation and Occupational Standards and the National Council for Evaluation and Academic Accreditation support these efforts. Another key issue targeted in adult education development is the professional development of the adult educators. In order to aid the development of a good quality learning, it is essential to promote the training of trainers and managers for a better adult education and training.

Because the cultural elements determine strategies, goals and operating modes, a healthy organization is less defined by the means of the financial return, but through the C.S.R., involving knowing and responding to the sustainability issues. Much discussed in the business world, the concept of a "learning organization" is a organization able to create, acquire and transfer knowledge and able to change its behavior, to reflect new knowledge by healthy insights. There is a strong relationship between the organizational culture, the practices of health protection and the human factor productivity, a relationship so strong that investing in people is seen as a wise strategy for achieving and maintaining high levels of business success. 


\section{Methods}

The methods were based on the interpretation of the opinions and attitudes as results of a questionnaire survey, a systematic observation of the concrete phenomena and synthesis of some previous studies in this area. The research was conducted by investigating a number of 1086 SMEs from all the fields of activity in the North East region of Romania where we can find about 10,43\% of the total number of SMEs from all over the country.

Methodological explanations: we used the stratified random type of inquiry, which reduced the sample weight in the homogeneous segments of the SMEs (such as those in the field of services) and enlarged weight for the heterogeneous segments (such as the industrial SMEs), thus ensuring a high quality of information and a high degree of accuracy in treating the investigated realities.

Significant aspects: the analyzed sample contains young companies, with up to 5 years of experience in business (34.4\%), the most common of the surveyed SMEs are organized as limited companies; the number of SMEs acting in the trade field, services, industry, tourism, transport and construction is prevalent and representative. The overall objective of the survey was to define the role of the lifelong learning in achieving performances inside the SMEs and the influence exercised by the organizational culture upon these performances.

The specific objectives of the survey questionnaire are based on:

- The perception of the knowledge-based economy and society among the surveyed SMEs managers;

- Which is the correlation between the concepts of knowledge based economy and society and the SMEs performances, in 2012;

- How the success factors of SMEs are defined and if among them we can find the employees' and managers' training;

- If the criteria for the appreciation of the employees' competence include their professional skills and their willingness to continuously improve their knowledge;

- What are the main issues related to the lifelong learning at the workplace and which is the financial support of this educational activity for adults.

We also based on the observations done several years, since 2009, upon the SMEs business and social behavior.

\section{Findings and results}

Regarding the managers' information and their adjustment to the trends towards the knowledge-based economy and society, from this analysis, a percentage, quite low, of $33,72 \%$, results from the surveyed firms, where these concepts are known. In the North-East region, these concepts are known and used by $34.32 \%$ of the interviewed managers.

The concept of knowledge based economy and society is perceived as a way to obtain performance only by the medium companies, having at least 15 years of activity, in the field of services and being conducted by well and high educated managers.

The appreciation of the SMEs managers regarding the key-factors for a successful business, underlines that the two first placed requirements are linked to the employees and their loyalty, skills and competence, as in table 1 . There is a tight connection between the age of the company and the perception about success, that is why younger firms appreciated the human resources' characteristics to be very important, while the aged companies (over 15-20 years activity) considered other factors to be of greater importance.

Unfortunately, among the main competitive advantages, the innovating capacity of 
the company is mentioned on the last place, only $2,16 \%$ of managers considering it as a path to overcome the competition, after some other factors, such as: quality of the results, lower prices, the employees 'qualification, distribution channels.

Table 1 Statistical data about the success factors in the analyzed SMEs.

\begin{tabular}{|l|l|}
\hline Competent and skilled employees & $31,80 \%$ \\
\hline Business partnerships & $31,70 \%$ \\
\hline Market opportunities for the products/services & $22,80 \%$ \\
\hline Loyal and satisfied employees & $10,70 \%$ \\
\hline $\begin{array}{l}\text { Support-services for the employees' charges } \\
\text { management }\end{array}$ & $1,80 \%$ \\
\hline Others & $1,20 \%$ \\
\hline
\end{tabular}

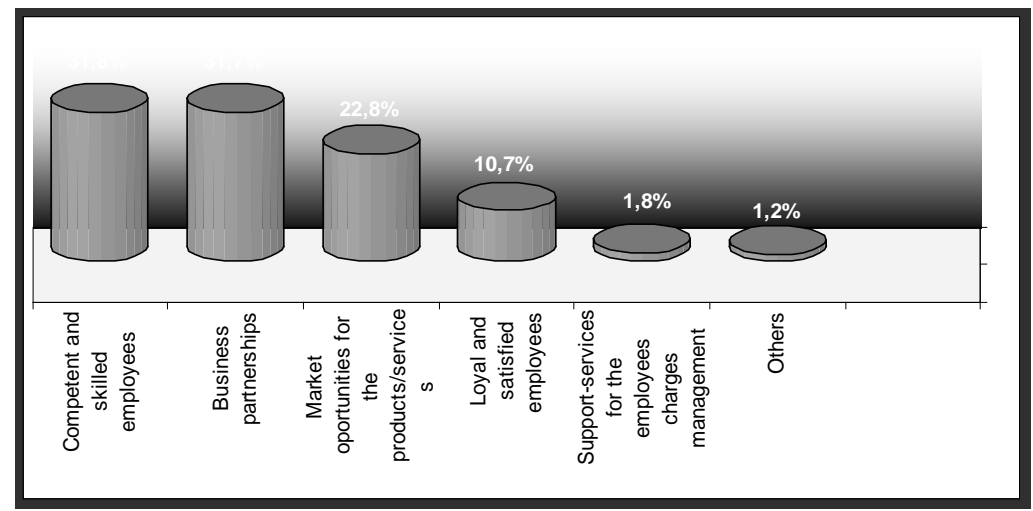

Figure 1 The graphic image of the main successful factors of the SMEs Source: original illustration

About the employees 'appreciation criteria that managers of SMEs in the North East region use, we can mention:

- $\quad$ the involvement in the organizational problems;

- $\quad$ the experience;

- $\quad$ the sense of responsibility;

- $\quad$ knowledge and held skills;

- $\quad$ the business competence;

- the teamwork skills;

- the consciousness;

- $\quad$ the loyalty towards the company;

- $\quad$ the capacity to make continuous efforts;

- $\quad$ the intelligence;

- $\quad$ the respectful behavior;

- $\quad$ the recommendations;

- $\quad$ the languages skills;

- the professional skills;

- $\quad$ the graduated school.

In the SMEs in the North East region managers attach certain importance to the training programmes and to the continuous education. Figure 2 explains the analysis of SMEs in the North East by the number of working days per employee dedicated to 
the training, in 2012 and their position among the SMEs from all over the country, treated by the same criteria:

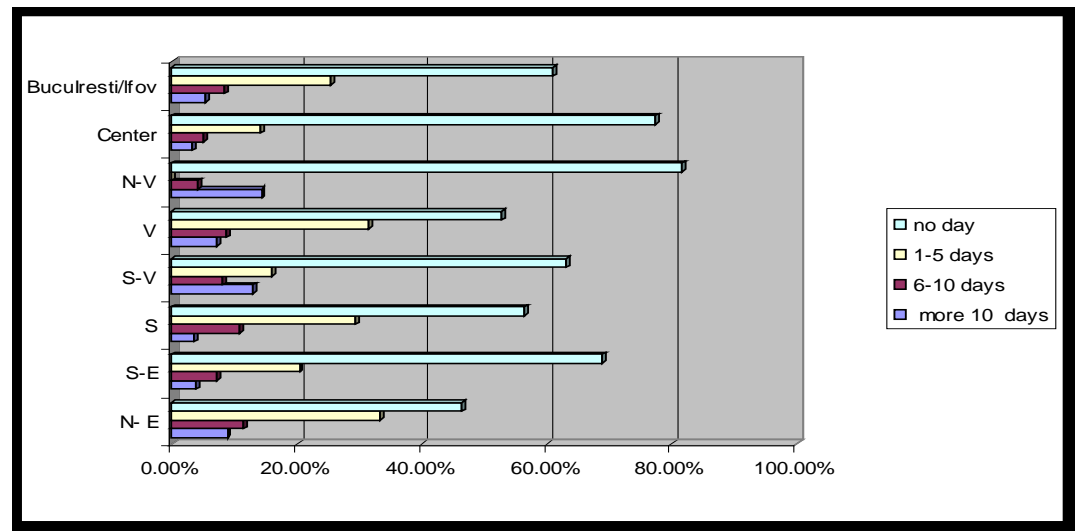

Figure 2 Average number of days devoted to the employees 'training in the SMEs in Romania.

Source: original illustration

From figures presented above, it can be easily seen that an important part of the SMEs in Romania, regardless of the region they belong, do not consider the human resources training activities as to be very important, and the lowest percentage have been registered, for the over 10 days allocated to human resources training activities, which demonstrates the efforts made by the employers for training; while the majority of SMEs have crossed through a difficult period, caused by the deep economic crisis in Romania and in other European countries. The North East region is characterized by the highest ratio of the companies that have allocated about 1-5 days for the employee training.

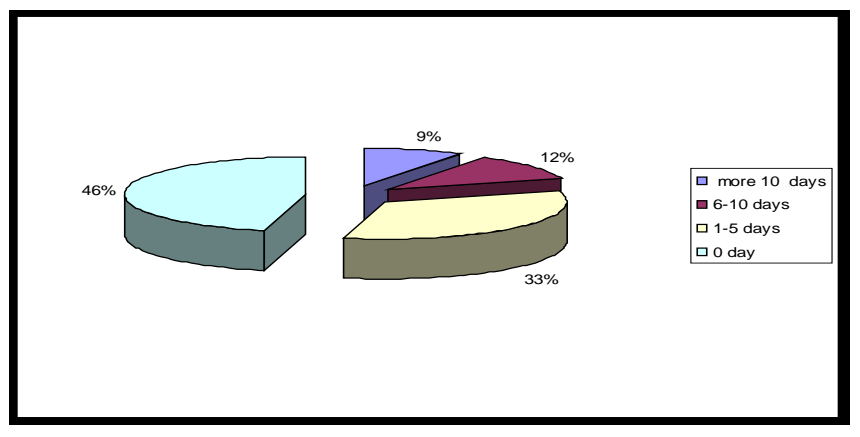

Figure 3 Average number of days devoted to the employees' training in the SMEs in the North-East region of Romania.

Source: original illustration

The results of this inquiry reflect a low availability to spend money for the implementation of lifelong education programmes, only maximum $2,19 \%$ of the income being yearly allocated to these activities, at the national level, in the North East region this percentage being larger, about 5,23\% of the yearly income.

To reinforce the idea that the managers of the SMEs in the North East region of the country are concerned about the human resources development, they facilitate the 
employees' participation to various programs to enable them in acquiring new attitudes, new knowledge and skills through large learning experiences, we presented the national situation about the days allocated to the training programmmes (see figure 3).

The employees of SMEs in the North East region who possess knowledge protect their knowledge resources and they devote to lifelong learning, not only for the employers' benefits, but also for themselves, in order to maintain and to increase their market value and, perhaps, to become indispensable for the employers. In this matter, the employee and the employer have different perspectives on the value of knowledge.

The SMEs in the North East part of the country can be designed as certain constructive learning organizations and the learning processes, both in organizations and for the individuals, are able to influence the way forward, through planned interventions.

\section{Conclusions}

Given the relatively low level of understanding and use of the concepts and tools of the knowledge-based economy and society, as a result of the data analysis, it is necessary for the policy makers in Romania to understand that the transition to the new economy is imminent and they must create appropriate policies and strategies to encourage the development of this type of economy.

The potential of the adult learning in the North-East region of Romania has not been yet fully exploited, in the analyzed last year: the participation in lifelong learning programmes varies greatly and it shows like unsatisfactory, in many Romanian SMEs, as well as below the EU's target for the average participation in lifelong learning ( $15 \%$ by 2020, for adults aged between 25-64 years old). In 2012, the average participation for the noted companies was under $5 \%$. The overall trend of the participation to long life leaning programmes is negative. Participation also decreases substantially in the case of low-skilled and older adults.

We concluded also that it is necessary that some programmes focusing on the teaching and study need lecturers attending courses for adult education and "alternative" education, as well as increasing the number of the organizations delivering these services, leaving the formal framework of the school or university. It aims to develop the adult education sector, as well as enable more people to accept learning experiences.

The lifelong learning has been recognized as an essential element of the European Higher Education Area since the European Education Ministers met in Prague, in 2001. The Prague Communiqué signals that in a Europe built on a knowledge-based society and economy, lifelong learning strategies are necessary to face the challenges of competitiveness, for the use of new technologies and to improve social cohesion, for equal opportunities and for a good quality of life.

Since then, the need to embed lifelong learning within higher education has been growing in its awareness, if we are to confront ourselves to the challenges of the future. In 2012, the Romanian officials' opinions and communiqués reaffirmed the role of the lifelong learning as one of the most important factors in meeting the needs of a changing labor market, and stressed the central role of the higher education institutions in transferring knowledge and strengthening regional development, including the continuous development of competences and the reinforcement of knowledge alliances. 


\section{References}

Argyris, C., \& Schön, D. (1978), Organizational learning: A theory of action perspective, Reading, Mass: Addison Wesley.

Cyert, R.M., and J.G. March. (1963), A Behavioral Theory of the Firm, Oxford: Blackwell.

Hedberg, Bo (1979), How Organizations Learn and Unlearn, Arbetslivscentrum.

Mahapatro B., (2010), Human Resources Management, New Age International (P) Ltd., Publishers, New Delhi.

Schön, D. A. (1991), The Reflective Turn: Case Studies In and On Educational Practice, New York: Teachers Press, Columbia University.

Senge, P. M., (1999), The Fifth Discipline. The Art and Practice of the Learning Organization, Random House, London.

Senge, P. M. (1990), The Fifth Discipline: The art and practice of the learning organization, Doubleday, New York.

Simon, H.A. (1969), The Sciences of the Artificial, Cambridge, MIT Press, first edition. 